\title{
Changes in trehalase activity and trehalose level during Ascaris suum (Nematoda) embryogenesis
}

\author{
M. DMITRYJUK ${ }^{1}$, K. ŻÓŁTOWSKA ${ }^{1}$, K. KUBIAK ${ }^{2}$, A. GŁOWIŃSKA ${ }^{1}$ \\ ${ }^{1}$ Department of Biochemistry, ${ }^{2}$ Department of Genetics, Faculty of Biology, University of Warmia and Mazury, \\ Oczapowskiego 1A, 10-957 Olsztyn, Poland; E-mail: m.dmit@uwm.edu.pl
}

\begin{abstract}
Summary
The levels of trehalose and the activity of trehalase during the development of Ascaris suum eggs were investigated. The level of trehalose in the zygote was high $(2.96 \pm 0.07$ $\mathrm{mg} / \mathrm{g})$. During cleavage of eggs, it decreased $(0.91 \pm 0.35$ $\mathrm{mg} / \mathrm{g}$ ). A higher concentration of the sugar was recorded at the blastula and during gastrulation, but it did not reach the uncleaved eggs level. In the early motile larvae, the concentration of trehalose was high $(4.58 \pm 2.01 \mathrm{mg} / \mathrm{g})$. It decreased with development of $\mathrm{L}_{1}$ larvae $(3.10 \pm 1.47 \mathrm{mg} / \mathrm{g})$. A rapid increase in trehalose reserves was observed between the $\mathrm{L}_{1}$ and $\mathrm{L}_{2}$ stages. The highest content of trehalose was found in invasive $\mathrm{L}_{2}$ larvae $(5.78 \pm 1.39 \mathrm{mg} / \mathrm{g})$.

The activity of trehalase at the zygote stage was high $(560.22 \pm 322.31 \mathrm{U} / \mathrm{mg})$. It decreased at the beginning of cleavage. It was the lowest at the $4-6$-cell stage (189.76 \pm $114.97 \mathrm{U} / \mathrm{mg}$ ). An increase in the enzyme activity occurred after reaching the blastula stage $(348.44 \pm 343.34 \mathrm{U} / \mathrm{mg})$. The highest trehalase activity was recorded during the $\mathrm{L}_{1}$ larvae stage $(635.72 \pm 251.16 \mathrm{U} / \mathrm{mg})$. The activity of that enzyme was about three times lower in the invasive stage larvae than in the $\mathrm{L}_{1}$ larvae.
\end{abstract}

Key words: trehalose; trehalase; glycogen; embryogenesis; Ascaris suum; nematode

\section{Introduction}

The eggs represent the dispersion stage during the life cycle of Ascaris suum and as such they are the most resistant form in the developmental cycle of the parasite (Rogers \& Petronoijevič, 1982). They possess that resistance thanks to three factors. First, to the construction of egg membranes composed of three layers - the internal consisting of ascarosides, middle - chitin and external - glycoproteins (Lyšek et al., 1985; Polyakowa-Krustewa et al., 1985), second, the large quantities of stored energy reserves (particularly triacylglycerols and carbohydrates) and finally, the ability to adjust the pace of metabolism to the external conditions (Anya, 1976). The development of embryos in A. suum eggs progresses according to the pattern typical for nematodes (Conn, 1991; Schierenberg et al., 1998). Cleavage is total and unequal. During gastrulation blastomeres collapse inward. After a couple of days the embryos elongate. The change in shape of embryos leads to the formation of the larvae $\mathrm{L}_{1}$. These larvae get through the first moult within the egg shell and becomes the invasive larvae. The $\mathrm{L}_{2}$ larvae penetrate the alimentary system of the host, most frequently per os, and there they hatch. Before they reach the mature form in the intestine, they migrate through liver, heart and lunges tissues of the host and get through three further moultes processes (Murrel et al., 1997).

The embryo of the nematode develops using in the internal environment owing to the substrates and their precursors accumulated in the egg during oogenesis (Passey \& Fairbairn, 1957). The hemolymph of the female is a rich source of them and a large part of the reserve compounds is transferred from it into the lumen of the ovary and stored in the oocytes. Also the cells of epithelium that form the ovary wall are able to produce nutritional materials (Foor, 1967). Much indicates that during embryogenesis of $A$. suum in aerobic environment reconstruction of energetic compounds within the egg takes place (Passey \& Fairbairn, 1957). Glycogen is the major reserve sugar in Ascaris eggs. Content and activity of enzymes of glycogen metabolism have already investigated in Ascaris adults (Dubinský et al., 1980; Turčeková et al., 1985, 1986). The changes in activity of $\alpha$-amylase, glycogen phosphorylase and content of glycogen during development of A. suum eggs were also studied (Źółtowska et al., 1998). Besides glycolgen, trehalose ( $\alpha$-D-glucopyranosyl-1,1- $\alpha$-D- glucopyranoside) also plays an important role (Behm, 1997).

In this study the content of trehalose and activity of the enzyme hydrolyzing it - trehalase during embryogenesis of A. suum were investigated. 


\section{Materials and Methods}

\section{In vitro culture and preparation of test samples}

The material for the study consisted of fertilized A. suum eggs isolated from bifurcation of uterus. The egg cultures were maintained at $27^{\circ} \mathrm{C}$ in $0.05 \mathrm{~mol} \mathrm{HCl}$. The level of egg development was determined every day. After reaching the defined development stage (zygote, 2-blastomere stage, 4 6 blastomere stage, $8-12$ blastomere stage, blastula, early and late gastrula, "tadpole" stage, early motile larvae, $\mathrm{L}_{1}$ and $\left.\mathrm{L}_{2}\right)$ samples were taken and were centrifuged $(200 \times \mathrm{g}$ for $5 \mathrm{~min}$ ) and weighed. The weighed portions (ca. $50 \mathrm{mg}$ ) were homogenized with $1 \mathrm{ml} 0.9 \% \mathrm{NaCl}$ in a manual Potter's homogenizer to obtain a uniform suspension with no cells. The homogenate obtained was centrifuged at $1500 \times$ $\mathrm{g}$ for $10 \mathrm{~min}$ in a refrigerated centrifuge. The supernatant obtained was used to determine the contents of protein, trehalose and activity of trehalase.

\section{Trehalose level determination}

In the supernatant intended for determination of trehalose content proteins and glycogen were precipitated using an equal volume of cold ethanol $\left(-12^{\circ} \mathrm{C}\right)$. Next the samples were centrifuged as above. The supernatant was dried at $50^{\circ} \mathrm{C}$ for $24 \mathrm{~h}$ and sediment obtained was dissolved in water. The sugars were assayed by HPLC on SCL-10A system (Shimadzu; Kyoto, Japan) equipped with a refractive index detector (Shimadzu, RID-10A), on a sodium column RNM Carbohydrate (Rezex, $300 \times 7.8 \mathrm{~mm}$ ) with a flow of $0.6 \mathrm{ml} \times \mathrm{min}^{-1}$, at $40^{\circ} \mathrm{C}$, and an eluent of $\mathrm{H}_{2} \mathrm{O}$. Under such conditions the mean reaction time of trehalose per $8.6 \mathrm{~min}$ using $1 \mathrm{mmol}$ standard trehalose solution by Sigma was measured. The content of trehalose was expressed in $\mathrm{mg}$ per $1 \mathrm{~g}$ of eggs.

\section{Enzymatic activity}

In the remaining part of the egg's extract trehalase activity was measured by the method of Dahlqvist (1968). The reactive mixture contained: $0.1 \mathrm{ml}$ of the extract from the eggs, $0.1 \mathrm{ml} 50 \mathrm{mmol}$ trehalose and $0.8 \mathrm{ml} 70 \mathrm{mmol}$ veronal sodium - sodium acetate buffer at $\mathrm{pH}$ 6.4. The reaction was carried out at $37^{\circ} \mathrm{C}$ for $1 \mathrm{~h}$. The quantity of glucose released from trehalose during the reaction was determined by the enzymatic method using glucose oxidase (LTS-120, Cormay, Lublin - Poland). Trehalase activity was expressed in enzymatic units [U]. One unit [U] represents the quantity of enzyme releasing $1 \mathrm{nmol}$ of glucose under the above conditions. The activity was converted to $1 \mathrm{mg}$ protein determined by the Lowry et al. method (1951). The results were subjected to statistic analysis using the Duncan test.

\section{Results}

1. Changes in trehalase activity during development of Ascaris eggs

During the zygote stage, the activity of trehalase was high $(560.22 \pm 322.31 \mathrm{U} / \mathrm{mg})$. The start of egg cleavage was accompanied by a decrease in enzyme activity by half. It remained at that lower level during the initial divisions and no statistically significant differences between the mean values from the discussed stages were found (Table 1). In the embryos during the late blastula stage the activity of trehalase was higher by ca. $50 \%$ as compared to the earlier stages and it remained at that level during the entire gastrulation stage. Another increase in trehalase activity occurred during the development of motile embryos and continued until achievement of the larval stage $\mathrm{L}_{1}$. During embryogenesis of $A$. suum the highest trehalase activity was found during the latter stage $(635.72 \pm 251.16 \mathrm{U} / \mathrm{mg})$. Statistically significant differences were recorded between the mean results obtained for $4-12$ blastomere embryos and $L_{1}(p<$ 0.05; Table 1). Development of the invasive $L_{2}$ larvae was accompanied by a decrease in the activity of the enzyme.

Table 1. Trehalase activity and trehalose concentration during development of Ascaris suum embryos

\begin{tabular}{|c|c|c|c|c|}
\hline Day & & Stage & $\begin{array}{l}\text { Trehalase activity } \\
\text { (U/mg of protein) }^{*}\end{array}$ & $\begin{array}{l}\text { Trehalose concentration } \\
\text { (mg/g of eggs) })^{*}\end{array}$ \\
\hline 1 & $\mathrm{a}$ & Zygote & $560.22 \pm 322.31$ & $2.96 \pm 0.07^{\bullet \bullet b-h}$ \\
\hline 3 & $b$ & $2 n$ & $257.53 \pm 125.37$ & $0.91 \pm 0.35^{\bullet \mathrm{fg} ; \bullet \bullet a, h-k}$ \\
\hline 7 & $\mathrm{c}$ & $4-6 n$ & $189.76 \pm 114.97$ & $0.99 \pm 0.40^{\bullet \mathrm{fg} ; \bullet \bullet \mathrm{fg}}$ \\
\hline 9 & $\mathrm{~d}$ & $8-12 n$ & $211.76 \pm 124.73$ & $1.17 \pm 0.32^{\bullet j ; \bullet \bullet a h i ~}$ \\
\hline 12 & e & Blastula & $348.44 \pm 343.34$ & $1.64 \pm 0.66^{\bullet i ; \bullet \bullet a k ~}$ \\
\hline 14 & $\mathrm{f}$ & Early gastrula & $297.34 \pm 289.44$ & $1.64 \pm 0.45^{\bullet b c i ; \bullet \bullet a k ~}$ \\
\hline 15 & $\mathrm{~g}$ & Late gastrula & $305.91 \pm 240.81$ & $1.63 \pm 0.47^{\bullet b c i ; \bullet \bullet a k ~}$ \\
\hline 17 & $\mathrm{~h}$ & Tadpole & $353.35 \pm 532.65$ & $2.29 \pm 0.43^{\bullet \mathrm{i} ; \bullet \bullet a-d}$ \\
\hline 21 & $\mathrm{i}$ & Motile larvae & $483.37 \pm 481.12$ & $4.58 \pm 2.01^{\bullet e-h ;} \cdot \bullet \bullet-d$ \\
\hline 23 & $\mathrm{j}$ & Larvae $\mathrm{L}_{1}$ & $635.72 \pm 251.16^{\bullet \mathrm{cdk}}$ & $3.10 \pm 1.47^{\bullet \bullet b c}$ \\
\hline 27 & $\mathrm{k}$ & Larvae $\mathrm{L}_{2}$ & $201.82 \pm 138.08$ & $5.78 \pm 1.39^{\bullet \bullet a-h, j}$ \\
\hline
\end{tabular}

${ }^{*}$ Mean $\pm \mathrm{SD} ; \mathrm{n}=5 ; \cdot \mathrm{p}<0.05 ; \cdot \mathrm{p}<0.01$ 
Trehalase activity at that stage was 3-times lower than in the $\mathrm{L}_{1}$ larvae. The difference between the averages for $\mathrm{L}_{1}$ and $\mathrm{L}_{2}$ was statistically significant (Table 1 ).

\section{Changes in trehalose level during embryogenesis of $A$. suum}

Major differences in the content of trehalose during the development of eggs of $A$. suum were recorded. The concentration of trehalose in zygotes was relatively high $(2.96 \pm$ $0.07 \mathrm{mg} / \mathrm{g}$ ). During cleavage of the eggs it decreased three fold and stayed at that level until the egg reached the blastula stage. Highly significant differences were recorded between the average obtained for the zygotes and the $2-$ 12-blastomeres ( $<<0.01$; Table 1). After the eggs had reached the blastula stage, the content of trehalose increased $(1.64 \pm 0.66 \mathrm{mg} / \mathrm{g})$ and remained at an almost constant level during the gastrulation processes. Another increase in trehalose content was recorded at the "tadpole" stage (stage 8). In the eggs with the early motile larvae, the content of trehalose was even higher $(4.58 \pm 2.01 \mathrm{mg} / \mathrm{g})$ than that recorded for the zygote. Statistically significant differences between the early motile larval stage and the earlier stages were recorded (Table 1). In $\mathrm{L}_{1}$ larvae the content of trehalose decreased to a level similar to that for the zygote. After reaching the invasive stage $\left(\mathrm{L}_{2}\right)$ a rapid increase in the sugar content $(5.78 \pm 1.40 \mathrm{mg} / \mathrm{g})$ was recorded. The concentration of trehalose was almost twice that in the zygote and $\mathrm{L}_{1}$ stages. The differences between the mean values for $\mathrm{L}_{2}$ and the other stages, except the motile larvae, were statistically highly significant (Table 1).

\section{Discussion}

Trehalose in nematodes has important physiological functions as it forms an energy reserve, it is a "circulating" sugar and a compound protecting against the environmental stress. It also participates in the mechanism of hatching the larvae from eggs (Behm, 1997; Pellerone et al., 2003). The role of trehalose as a cryoprotectant has been described for Antarctic nematodes Panagrolaimus davidi (Wharton et al., 2000). It is known that it also protects nematodes against drying (Womersley \& Higa, 1998). The effect of thermal acclimation on trehalose accumulation has been observed in entomopathogenic nematodes (Jagdale \& Grewal, 2003). Eggs of A. suum developing in the external environment are particularly exposed to drying and freezing. The normal embryogenesis requires, as already mentioned, accumulating high energy reserves. According to Passey and Fairbairn (1957) the eggs of A. suum, during the initial period of development use mainly trehalose as the energy source. Our results confirm that observation. Trehalose content during development of $A$. suum eggs very changed. The numerous statistically significant differences support this.

The activity of trehalase at the zygote stage was relatively high. It resulted in a rapid decrease in trehalose content during cleavage of the egg. Our earlier studies indicate that at cleavage, egg glycogen is the main source of energy. The activity of glycogen phosphorylase during that development period was twice that in the zygote (Źółtowska et al., 1998). In that time the activity of trehalase during cleavage decreased. Only after the eggs had reached the stage of late blastula, did the activity of the enzyme increase and was maintained during the gastrulation processes at the almost constant level. That is the period of extensive changes involved in movement and differentiation of blastomers requiring high outputs of energy.

Both in case of glycogen (Źółtowska et al., 1998), and trehalose, a gradual increase in sugar contents was observed during the period from blastula to early motile larvae. Probably restoring the reserves of carbohydrates is possible from lipids. Fertilized eggs contain high quantities of triacylglycerols, roughly ca. $36 \%$ of dry weight (Beis \& Barrett, 1975). During the development of larvae in eggs in aerobic conditions, gradual utilization and partial transformation of fats into sugars takes place (Passey \& Fairbairn, 1957).

The highest level of trehalase activity during the development of Ascaris eggs was recorded at $\mathrm{L}_{1}$ stage, where were also noticed statistically significant differences. It accompanied by a decrease in trehalose content. It can be assumed that trehalose is a significant source of energy for moult of $\mathrm{L}_{1}$ larvae and maturing of $\mathrm{L}_{2}$ larvae. On the other hand, an almost three-fold decrease in activity of the enzyme as compared to $\mathrm{L}_{1}$ larvae was observed in $\mathrm{L}_{2}$ larvae reaching the invasive form. That phenomenon may be linked to a slowing of basic metabolism, that is characteristic of the dispersion and invasive stages of parasites on one hand (Rogers \& Petronoijevič, 1982), and the necessity to accumulate large enough reserves of trehalose on the other. The eggs in that form usually stay alive for long periods in the external environment waiting for the host. The accumulation of trehalose before long periods of dormant phase was observed by Nambu et al. (1997) during the embryonic development of shrimps. What is more, that sugar plays an important role in hatching of larvae from eggs (Behm, 1997). Trehalose is present mainly in periviteline liquid (Faibairn \& Passey, 1957). As a low molecular compound that does not penetrate through cellular membranes, the disaccharide increases the osmotic pressure within the egg. Further, the increase of solubility of egg's shells leads to an outflow of soluble substances in the periviteline liquid and an inflow of water into the egg. Those factors, together with the intense motions of the growing juvenile form of the parasite leads to release of the larvae from egg membranes (after Behm, 1997). We assume that accumulation of large quantities of trehalose during the last stage of embryonic development of $A$. suum takes place at the cost of glycogen, the content of which decreases during that period (Żółtowska et al., 1998).

In conclusion it can be observed that increases in trehalase activity during the process of Ascaris embryogenesis always precedes the processes involving high energy output, such as blastulation, gastrulation and moult of $\mathrm{L}_{1}$ larvae. The activity level of the enzyme is a measure of trehalose utilization rate by the developing embryo, and trehalose 
content may be considered a measure of the rate of cellular metabolism during embryonic development of the A. suum eggs. A high content of the sugar after reaching the blastula stage and during gastrulation are consistent with the knowledge that this disaccharide fulfills the function of a substance protecting the tissues of the still poorly developed embryo against harmful environmental effects. Comparing the changes in concentrations of glycogen and triacylglycerols during embryogenesis of A. suum it can be assumed that the level of trehalose in the eggs of the parasite is maintained owing to gradual utilization of the above compounds. It should be stressed that the concentration of trehalose in the invasive larvae is double that in the zygote. This is linked to the role of trehalose during hatching of the larvae and the necessity to protect the larvae during the time of waiting for the suitable host.

\section{References}

ANYA, A. O. (1976): Physiological aspects of reproduction in nematodes. Adv. Parasitol., 14: $267-351$

BEHM, C. A. (1997): The role of trehalose in the physiology of nematodes. Int. J. Parasitol., 27: 215 - 229

BEIS, L., BARRETT J. (1975): Energy metabolism in developing Ascaris lumbricoides eggs. II. The steady state content of intermediary metabolites. Develop. Biol., 42: $188-$ 195

ConN, D. B. (1991): Atlas of Invertebrate Reproduction and Development. A John Wiley and Sons, INC., Publication, New York - Chichester - Brisbane - Toronto - Singapore: $70-89$

DAHLQVIST, A. (1968): Assay of intestinal disaccharidases. Anal. Biochem., 22: 99 - 107

DMITRYJUK, M., ŻóŁTOWSKA, K. (2004): Trehalose catabolism enzymes in tissues of Ascaris suum (Nematoda). Helminthologia, 41: $63-66$

DuBINSKÝ, P., RYBOŠ, M., TURČEKOVÁ, L. (1980): Distribution of glycogen in Ascaris suum and Parascaris equorum (Nematoda) males and females. Zool. Anz. (Jena), 204: $147-153$

FAIRBAIRN, D., PASSEY, R. F. (1957): Occurrence and distribution of trehalose and glycogen in the eggs and tissues of Ascaris lumbricoides. Exp. Parasitol., 6: 566 - 574

FOOR, W. E. (1967): Ultrastructural aspects of oocyte development and shell formation in Ascaris lumbricoides. $J$. Parasitol., 53: 1245 - 1261

JAGDALE, G. B., GRewAL, P. S. (2003): Acclimation of entomopathogenic nematodes to novel temperatures: trehalose accumulation and the acquisition of thermotolerance. Int. J. Parasitol., 33: 145 - 152
Lowry, O. H., Rosebrough, N. J., FARR, A. L., RANDALl, R. J. (1951): Protein measurement with the Folin phenol reagent. J. Biol. Chem., 193: 265 - 275

LYŠEK, H., MALINSKI, J., JANISH, R. (1985): Ultrastructure of eggs of Ascaris lumbricoides Linnaeus 1758 - I. Eggshells. Folia Parasitol., 32: 381 - 384

Murrel, K. D., ERIKSEn, L., NAnsen, P., Slotved, H.-C., RASMUSSEN, T. (1997): Ascaris suum: a revision of its early migratory path and implications for human ascariasis. $J$. Parasitol., 83: 255 - 260

NAMBU, Z., NAMBU, F., TANAKA, S. (1997): Purification and characterization of trehalase from Artemia embryos and larvae. Zool. Sci., 14: 419 - 427

PASSEY, R. F., FAIRBAIRN, D. (1957): The conversion of fat to carbohydrate during embryonation of Ascaris eggs. Can. J. Biochem. Physiol., 35: 512 - 535

Pellerone, F. I., Archer, S. K., Behm, C. A., Grant, W. N., Lacey, M. J., Somerville, A. C. (2003): Trehalose metabolism genes in Caenorabditis elegans and filarial nematodes. Int. J. Parasitol., 33: 1195 - 1206

Polyakova-Krusteva, O., BRuŇANSKÁ, M., DubinskÝ, P. (1985): The influence of fertilization on the ultrastructure of Ascaris suum eggs. Helminthologia, 22: 233 - 244 Rogers, W. P., Petronoijevič, T. (1982): In Symons L.E.A., Donald A.D., DineEN J. K (Eds): The invasive stage and the development of Nematodes. Biology and control of endoparasites. Academy Press. Australia (Sydney, N.Y., London): $3-28$

SchierenberG, E., Wiegner, O., Bossinger, O., SKibA, F., Kutzowitz, M. (1998): Pattern formation and cell specyfication in nematode embryos: A theme with considerable variations. Zoology, 100: $320-327$

TurČekovÁ, L., Zemek, J., Dubinský, P., RyBoš, M. (1985): The glycogen synthase activity of muscles and reproductive organs of Ascaris suum females. Helminthologia, 22: $47-54$

TURČEKOVÁ, L., ZEMEK, J., DUBINSKÝ, P., RYBOŠ, M. (1986): Phosphorylase $\mathrm{a}$ and $\mathrm{b}$ activity in the muscle and reproductive organs of Ascaris suum females. Helminthologia, 23: $79-84$

Wharton, D. A., Judge, K. F., Worland, M. R. (2000): Cold acclimation and cryoprotectants in freeze-tolerant Antarctic nematode, Panagrolaimus davidi. J. Comp. Physiol. B, 170: $321-327$

Womersley, C. Z., HigA, L. M. (1998): Trehalose: its role in the anhydrobiotic survival of Ditylenchus myceliophagus. Nematologica, 44: $269-291$

ŻóŁtowska, K., DMitryJuk, M., Demianowicz, W. (1998): Glycogen phosphorylase activity and glycogen concentration in developing eggs of Ascaris suum (Nematoda). Acta Biol. Crac. Zool., 40: $81-84$ 